\title{
FAUNA PARASITOLÓGICA DE ALEVINOS DE MATRINCHÃ Brycon cephalus (GÜNTHER, 1869) COLETADOS NOS RIOS NEGRO E SOLIMÕES, NA AMAZÔNIA CENTRAL ${ }^{1}$
}

\author{
Sanny M. Sampaio de ANDRADE ${ }^{2}$, José Celso de O. MALTA², Evaldete \\ FERRAZ $Z^{2}$
}

\begin{abstract}
RESUMO - Aproximadamente 2500 alevinos de matrinchã com comprimento padrão de 0,8 a $5,0 \mathrm{~cm}$ foram coletados no lago Catalão, margem direita do río Negro e no rio Solimões, próximo a ilha da Marchantaria, Estado do Amazonas. Uma subamostra de 136 peixes foi retirada para exames parasitológicos e o restante foi colocado em tanques em uma estação de piscicultura, durante 30 dias. Após esse período uma segunda amostra foi retirada e examinada. Dos 136 peixes: $49(36 \%)$ estavam parasitados com metacercárias de trematódeos; 32(23,5\%) com nematóides Spirocamallanus inopinatus; $26(19 \%)$ com monogenóideos Jainus amazonensis; $3(2 \%)$ com protozoários Trichodina sp.; $1(0,7 \%)$ com acantocéfalo Echinorhynchus sp. e $2(1,5 \%)$ com estágios larvais de cestóides. Dos peixes mantidos nos tanques, após 30 dias foi examinada uma subamostra de 60 peixes: $42(70 \%)$ estavam parasitados com J. amazonensis; $14(23 \%)$ com S. inopinatus; $9(15 \%)$ com metacercárias de trematódeos e 2(3\%) com Echinorhynchus sp. A intensidade média e abundância média foram maiores em $J$. amazonensis (342 e 65), seguido por cestóides (70 e 1), Trichodina sp. (13 e 0,3), trematódeos (5 e 2), S. inopinatus (1 e 0,3) e Echinorhynchus sp. (1 e 0,007). Na estação de piscicultura a intensidade média e abundância média também foram maiores para o $\mathrm{J}$, amazonensis (222 e 115) em relação aos demais grupos. A espécie $J$. amazonensis apresentou maior intensidade média e menor prevalência na natureza. Houve variação na composição da fauna parasitógica e nos indices de infestação, após 30 dias de permanência na estação de piscicultura.
\end{abstract}

Palavras-chaves: parasitas-peixes, Brycon cephalus, peixe da natureza, índices parasitários.

Parasitological Fauna of Matrinchã Fries Brycon cephalus (Günther, 1869) Collected in Negro and Solimões Rivers, in Central Amazônia.

Abstract - Nearly 2,500 fries of Brycon cephalus with a standard length from 0.8 to $5.0 \mathrm{~cm}$ were collected in Catalão Lake, on the right bank of Negro River and close to Marchantaria Island in Solimões River, in the State of Amazonas. A sample of 136 fishes was taken for parasitological examination and the remaining were placed in tanks at a fish farming station for 30 days. Of the 136 fishes $49(36 \%)$ were infected by trematodes metacercariae, $32(23,5 \%)$ by the nematode Spirocamallanus inopinatus, $26(19 \%)$ by the monogenoidea Jainus amazonensis, $3(2 \%)$ by the protozoan Trichodina sp., 1 $(0,7 \%)$ by the acanthocephala Echinorhynchus sp. and $2(1,5 \%)$ by stages of cestoda larval. After 30 days a sample of 60 fish from the fish kept in the tanks was examined: $42(70 \%)$ were infected by $J$, amazonensis, $14(23 \%)$ by $S$. inopinatus, $9(15 \%)$ by trematode metacercariae and $2(3 \%)$ by Echinorhynchus sp. The highest average intensity and abundance values were observed related to J. amazonensis (342 and 65), followed by $S$. inopinatus ( 1 and 0,3), Trematoda (5 and 2), Cestoda (70 and 1), Echinorhynchus sp. (1 and 0,007) and Trichodina sp. ( 13 and 0,3$)$. At the fish farming station the average intensity and abundance values were also higher for $J$, amazonensis (222 and 115) in relation to the other groups. On the other hand, $J$. amazonensis presented the highest average intensity and the lowest prevalence values in the wild. There was a variation on the parasitological fauna and infestation indexes after 30 days of permanence at the fish farming station.

Key-words: parasite-fish, Brycon cephalus, wild fish, parasitary indexes.

${ }^{1}$ Parte da dissertação de mestrado do Programa de Pós-Graduação do INPA em Biologia de Água

Doce e Pesca Interior

${ }^{2}$ Laboratório de Parasitologia e Patologia de Peixes do INPA. 


\section{INTRODUÇÃO}

Os peixes são os vertebrados que apresentam os maiores indices de infestação por parasitas, devido às peculiaridades do meio aquático que facilitam a

propagação, complementação do ciclo de vida e outros fatores de relevante importância para a sobrevivência de cada grupo de organismos parasitas (Malta, 1984).

As doenças em peixes têm aspectos diferentes de acordo com a origem dos hospedeiros, seja de populações do ambiente natural, seja de piscicultura. Nesses ambientes, as condições são bastante distintas, devido a fatores como: altas densidades populacionais, tipo de alimentação, degradação da qualidade de água, manuseio dos exemplares e execução de tratamentos que provocam estresse nos hospedeiros (Obiekezie \& Taege, 1991).

Nos ambientes naturais, os peixes possuem uma variedade de patógenos, no entanto, não apresentam geralmente sinais clinicos de nenhuma espécie de parasita.. Normalmente, isso acontece, devido ao estado nutricional e físiológico do peixe estar em equilibrio com o ambiente, evitando a manifestação da doença. Quando porém, ocorrem alterações ambientais, com reflexos nos mecanismos de defesa dos peixes, imediatamente poderão levar esses animais a manifestarem sinais clínicos de certas enfermidades, já que passam a se tornar sujeitos à ação dos patógenos (Pavanelli et al., 1998).

A espécie em estudo, o matrinchã Brycon cephalus (Günther, 1869), possui grande importância para a pesca e piscicultura na regiào amazônica. Suas doenças parasitárias, no ambiente natural, são pouco conhecidas e a maioria dos parasitas descritos para o gênero Brycon na natureza foram obtidos de peixes no estágio adulto.

Os parasitas citados para as várias espécies de Brycon do ambiente natural são: $B$. brevicaudata Günther, 1864; o nematóide Spirocamallanus inopinatus Travassos, 1929; B. cephalus, o copépodo Amplexibranchius bryconis Thatcher \& Paredes, 1985; Brycon falcatus Müller \& Troschel 1844; o nematóide Rhabdochona acuminata Molin, 1860; B. hilarii, o nematóide $S$. inopinatus, o acantocéfalo Echinorhynchus bryconis Machado Filho, 1959; B. lundii Lütken, 1875, o trematódeo Dendrorchis neivai Travassos, 1926; e $B$. erythroptherum Cope, 1872 os monogenóideos Anacanthorus brevis Mizelle \& Kritsky, 1969, A. elegans Kritsky, Thatcher \& Kayton, 1979, A. kruidenieri Kritsky, Thatcher \& Kayton, 1979, A. spiralocirrus Kritsky, Thatcher \& Kayton, 1979, Jainus amazonensis Thatcher \& Kayton, 1980, Tereancistrum kerri Thatcher \& Kayton, 1980, T. ornatus Thatcher \& Kayton, 1980, Trinibaculum braziliensis Thatcher \& Kayton, 1980, o nematóide S. inopinatus e o copépodo Ergasilus bryconis Thatcher, 1981 (Thatcher, 1991).

Devido aos problemas taxonômicos do gênero Brycon, existe somente uma espécie de parasita que tem o B. cephalus, como hospedeiro, 
- copépodo Amplexibranchius bryconis (Thatcher, 1991). ZaniboniFilho et al. (1988) colocaram $B$. cephalus como sinonimia de $B$. erythroptherum, desta forma, todos os parasitas do segundo hospedeiro são comuns ao primeiro.

Em um estudo com os crustáceos branquiúros parasitas de peixes do lago Janauacá, um lago de várzea da margem direita do rio Solimões, sete exemplares de Brycon cf. melanopterus Cope, 1872, foram examinados e nenhum ocorreu parasitado (Malta, 1981). Em 1983, um $B$. cf. melanopterus foi coletado parasitado por cinco exemplares de Dipteropeltis hirundo Calman, 1912, no igarapé Traíra, na Reserva Ducke, próximo de Manaus, Amazonas (Malta, com. pessoal).

Pizango-Paima (1997) estudando $B$. cephalus adultos da natureza, encontrou o isópodo Braga sp., na cavidade bucal aderido à língua; três espécies de nematóides, $S$. inopinatus, Cucullanus sp. e Rabdochona sp.

A obtenção de alevinos de matrinchã na natureza é um procedimento freqüente na região. Atualmente, algumas estações de piscicultura estão produzindo alevinos desta espécie intensivamente, para poder suprir a demanda dos cultivos. No entanto, quando esses peixes são coletados na natureza, precisa-se conhecer as condições de saúde destes animais. Portanto, estudos para se diagnosticar as doenças parasitárias do matrinchã são de grande relevância para o manejo da espécie. O objetivo deste trabalho foi estudar a fauna parasitológica de alevinos capturados na natureza e avaliar sua variação após 30 dias em uma estação de piscicultura.

\section{MATERIAL E MÉTODOS}

Foram capturados pelos técnicos da Coordenação de Pesquisas em Aquacultura do INPA cerca de 2500 alevinos de matrinchã durante os meses de janeiro e fevereiro de 1998 , no lago Catalão, margem direita do rio Negro e rio Solimões, próximo à ilha da Marchantaria. Para estudo da parasitofauna foi retirada uma subamostra de 136 peixes com 0,8 a $5,0 \mathrm{~cm}$ de comprimento padrão. O restante foi mantido em um tanque de alvenaria, com fundo de terra, em uma estação de piscicultura. Após 30 dias, foi feita uma segunda subamostragem de 60 alevinos para análise da fauna de parasitas.

Os peixes foram colocados inteiros em placa de Petri com água destilada para verificação de sinais clínicos. Os peixes muito pequenos foram colocados sobre uma lâmina com uma gota de água destilada e cobertos com uma lamínula. Efetuouse uma pressão sobre a lamínula para observação dos órgãos internos. Lâminas de esfregaço de sangue foram feitas em $25 \%$ dos peixes amostrados para verificar a presença de parasitas sangüíneos e coradas pelo método de Giemsa (Bier, 1975). E o ram feitas lâminas temporárias de raspado de pele, nadadeiras, opérculo e brânquias e da mucosa dos órgãos internos. Os arcos branquiais e os 
órgãos internos foram removidos e separados em placas de Petri, com água destilada, sendo examinados em microscópio estereoscópio e óptico.

Para estudo dos monogenóideos, metade dos arcos branquiais foi colocada em formalina fosfatada tamponada a $10 \%$. A outra metade foi individualizada e colocada em frasco com tampa contendo formalina 1:4000. Posteriormente, os monogenóideos foram coletados com uma pipeta de Pasteur ou pincel fino $\mathrm{n}^{0} 0$ e colocados em frascos de $15 \mathrm{ml}$ contendo álcool $70 \%$ (Shinn et al., 1993). Lâminas permanentes foram feitas utilizando-se solução de Malmberg (Malmberg, 1970). A identificação dos monogenóideos foi baseada nos trabalhos de Kritsky et al. (1980) e Thatcher (1991). Holótipos e parátipos depositados na Coleção de Invertebrados do INPA foram utilizados para auxiliar na identificação. Os demais parasitas foram preparados e identificados conforme as técnicas de Amato et al. (1991) e Thatcher (1991).

Os índices parasitários foram expressos conforme Margolis et al. (1982) revisado por Bush et al. (1997). Os índices utilizados para estimar o tamanho das populações de parasitas nos peixes foram prevalência, intensidade, intensidade média e abundância média.

Amostras das espécies de parasitas e do hospedeiro foram depositadas na Coleção de Invertebrados (acervo de Platyhelminthes) e na Coleção de Peixes do Instituto Nacional de Pesquisas da
Amazônia. As espécies Jainus amazonensis (INPA 385), Spirocamallanus inopinatus (INPA 387), Anacanthorus spiralocirrus (INPA 386) e Brycon cephalus (INPA 15902) foram depositadas em vidros com alcool $70 \%$. As espécies Trinibaculum brazilensis (INPA 388 ab) e Tereancistrum kerri (INPA 399 ac) foram depositadas em lâminas permanentes.

\section{RESULTADOS \\ Peixes provenientes da natureza}

Dos 136 peixes necropsiados, $49(36 \%)$ estavam parasitados com trematódeos, $32(23,5 \%)$ com nematódeos, $26(19,11 \%)$ com monogenóideos, $3(2,2 \%)$ com protozoários, $2(1,47 \%)$ com estágios larvais de cestódeos e $1(0,73 \%)$ com acantocéfalos.

Os exames macroscópicos dos alevinos de $B$. cephalus provenientes da natureza não revelaram a ocorrência de nenhum sinal clínico ou anormalidade no aspecto externo dos peixes.

As análises das lâminas de esfregaço de sangue mostraram-se negativas para parasitas sangüíneos nos 34 peixes amostrados. As lâminas temporárias de raspados de brânquias evidenciaram a presença do protozoário Trichodina sp. Ehrenberg, 1834 e massivas infestações do monogenóideo Jainus amazonensis (Fig. 1), acompanhadas de intensa produção de muco.

O exame parasitológico interno registrou a ocorrência de trematódeos nos estágios de metacercárias e larvas plerocercóides de cestóides, as quais 
encontravam-se dispostas em forma de cachos de uva sob os cecos pilóricos e intestino. $\mathrm{O}$ acantocéfalo Echinorhynchus sp. Zoega in Müller, $1776 \mathrm{e}$ - nematóide Spirocamallanus inopinatus foram detectados na porção anterior do intestino.

As metacercárias de trematódeos apresentaram a prevalência mais alta, parasitando $36 \%$ dos peixes. Os demais indices de intensidade, intensidade média e abundância média foram mais altos para o monogenóideo Jainus amazonensis. Os indices parasitários das espécies de parasitas do matrinchã estão na tabela 1 .

\section{Peixes provenientes da estação de piscicultura}

Dos 60 peixes necropsiados, $42(70 \%)$ encontravam-se parasitados com monogenóideos, 14(23\%) com nematóides, $\quad 9(15 \%) \quad$ com metacercárias de trematódeos e $2(3 \%)$ com acantocéfalos.

As análises das lâminas de esfregaço de sangue mostraram-se negativas para parasitas sangüíneos nos 15 peixes amostrados. Os exames macroscópicos nos alevinos de matrinchã provenientes da estação de piscicultura não revelaram a ocorrência de nenhum sinal clínico. As lâminas temporárias de raspado de brânquia detectaram massivas infestações do monogenóideo Jainus amazonensis.

$\mathrm{O}$ exame parasitológico interno

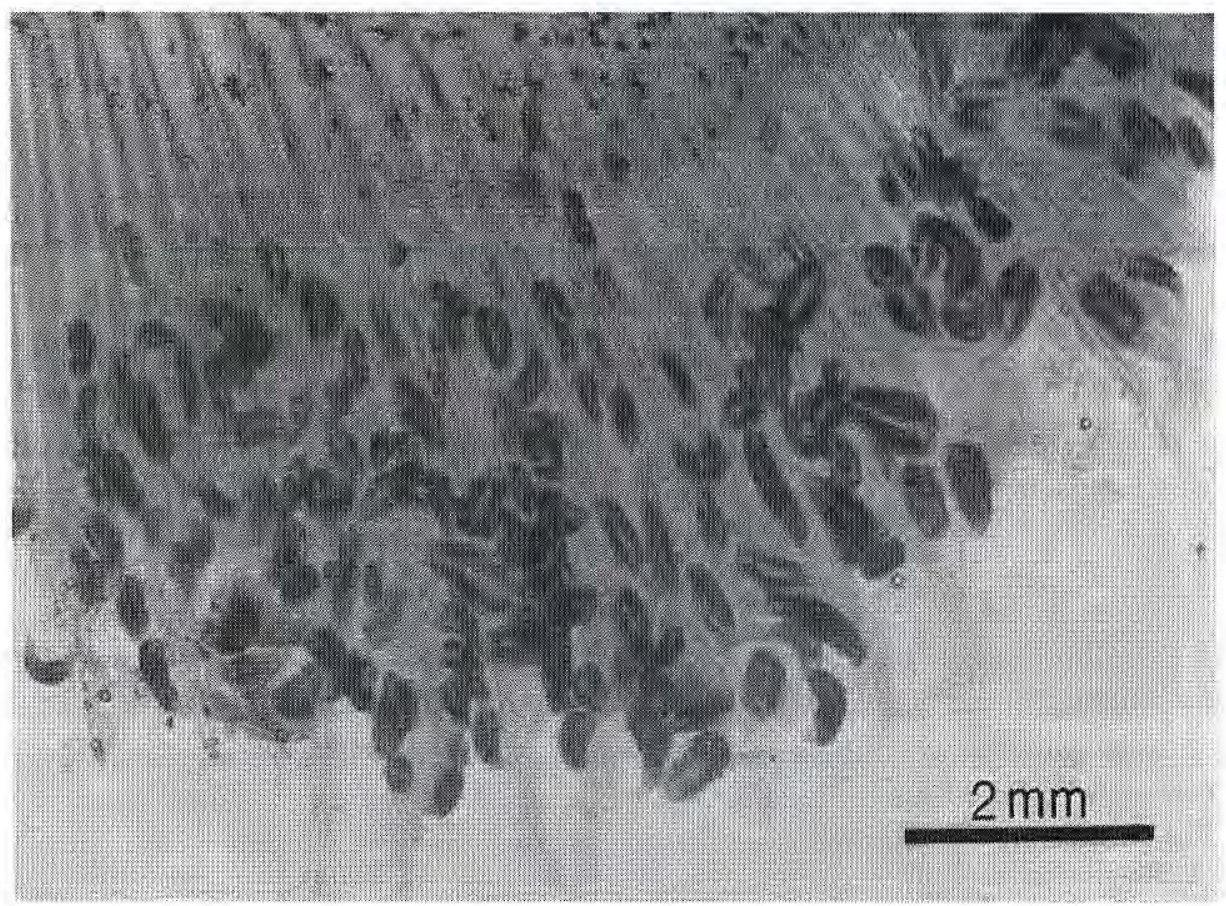

Figura 1. Fotomicrografia de luz da brânquia de um alevino de Brycon cephalus (Günther, 1869) coletado na natureza, parasitada por Jainus amazonensis (Monogenea: Dactylogyridae). 
registrou a ocorrência de metacercárias de trematódeos, do nematóide Spirocamallanus inopinatus e do acantocéfalo Echinorhynchus sp. A espécie de parasita mais prevalente foi o monogenóideo $J$. amazonensis, presentes em $70 \%$ dos peixes amostrados. Os indices mais altos de intensidade, intensidade média e abundância média foram também desta espécie. Os índices parasitários das espécies de parasitas do matrinchã da estação de piscicultura estão apresentados na tabela 2 .

\section{DISCUSSÃO}

No ambiente natural, geralmente, há um relacionamento estável entre o parasita e o hospedeiro. Sistemas de regulação foram desenvolvidos para assegurar que a carga parasitária não aumente e ameace a vida do peixe (Southgate, 1993). Os peixes na natureza, geralmente, carregam uma variedade de parasitas que raramente são fatais, a menos que, mudanças no meio ambiente, propiciem condições nas quais os organismos patogênicos. normalmente em equilíbrio com o peixe, se multipliquem e

Tabela 1. Índices parasitários de alevinos de Brycon cephalus (Günther, 1869) coletados no lago Catalão e no rìo Solimões, próximo à ilha da Marchantaria.

\begin{tabular}{lcccc}
\hline Parasita & $\begin{array}{c}\text { Prevalência } \\
(\%)\end{array}$ & Intensidade & $\begin{array}{c}\text { Intensidade } \\
\text { média }( \pm \mathrm{EP})\end{array}$ & $\begin{array}{c}\text { Abundância } \\
\text { média }( \pm \mathrm{EP})\end{array}$ \\
\hline J. amazonensis & 19,0 & $2-2679$ & $342,4( \pm 130)$ & $65,4( \pm 27)$ \\
S. inopinatus & 23,5 & $1-3$ & $1,2( \pm 0,08)$ & $0,3( \pm 0,05)$ \\
Metacercária & 36,0 & $1-25$ & $5,3( \pm 0,74)$ & $1,9( \pm 0,34)$ \\
$\begin{array}{l}\text { Estágio larval de } \\
\text { Cestóide }\end{array}$ & 1,5 & $30-110$ & $7,00( \pm 24)$ & $1,0( \pm 0,83)$ \\
$\begin{array}{l}\text { Echinorhynchus sp. } \\
\text { Trichodina sp. }\end{array}$ & 0,7 & 1 & 1,0 & 0,007 \\
\hline
\end{tabular}

(士EP) Erro padrão da média

Tabela 2. Índices parasitários de alevinos de Brycon cephalus coletados na estação de piscicultura.

\begin{tabular}{lcccc}
\hline \multicolumn{1}{c}{ Parasita } & $\begin{array}{c}\text { Prevalência } \\
(\%)\end{array}$ & Intensidade & $\begin{array}{c}\text { Intensidade } \\
\text { média }( \pm \mathrm{EP})\end{array}$ & $\begin{array}{c}\text { Abundância } \\
\text { média }( \pm \mathrm{EP})\end{array}$ \\
\hline J. amazonensis & 70,0 & $1-2400$ & $222,4( \pm 90,16)$ & $115,7( \pm 64,77)$ \\
S. inopinatus & 23,3 & $1-2$ & $1,1( \pm 0,09)$ & $0,2( \pm 0,06)$ \\
mertacercária & 15,0 & $2-25$ & $7,6( \pm 1,86)$ & $1,1( \pm 0,5)$ \\
Echinorhynchus sp. & 3,3 & $1-2$ & $1,5( \pm 0,48)$ & $0,05( \pm 0,03)$ \\
\hline
\end{tabular}

( \pm EP) Erro padrăo da média 
desencadeiem a ocorrência de doenças (Branson, 1993).

Trematódeos digenéticos da espécie Dendrorchis neivai, Travassos, 1926 já haviam sido registrados, na natureza, infectando Brycon lundi. Porém, não havia registro desse grupo de parasita infectando outras espécies do gênero Brycon. Neste trabalho, os trematódeos digenéticos, nos estágios de metacercárias, foram os parasitas mais freqüentes nos peixes procedentes da natureza, com prevalência de $36 \%$. Este foi o primeiro registro de um trematódeo parasitando Brycon cephalus. Os locais mais infectados pelas metacercárias foram os cecos pilóricos e o intestino. Entretanto, nenhuma patogenicidade foi visualizada no local de infecção.

A classe Cestoda é representada em peixes amazônicos pelas ordens Proteocephalidea, Tetraphyllidea e Trypanorhyncha (1 gênero e espécie). As duas últimas ocorrem em arraias, exceto uma espécie de Tetraphyllidea (Thatcher, 1991). A ordem Proteocephalidea é, principalmente parasitas de peixes, mas algumas espécies são encontradas em anfíbios e répteis. No estágio larval, caracteriza-se pela larva (plerocercóide) possuindo escólex com quatro ventosas (Rego et al., 1999). A familia Proteocephalidae apresenta o escólex com quatro ventosas musculares em forma de copa; uma quinta ventosa pode aparecer no ápice do escólex (Thatcher, 1991).

Neste trabalho, os estágios larvais de cestóides foram observados associados as metacercárias nos cecos pilóricos e intestino. Lâminas temporárias dos cestóides dissecados, evidenciaram a presença das quatro ventosas, mostrando que os indivíduos pertencem a ordem Proteocephalidea. Este foi o primeiro registro de um proteocefalideo parasitando um peixe da subfamília Bryconinae na América do Sul.

Os valores de prevalência e intensidade do nematóide $S$. inopinatus em Brycon cephalus adultos provenientes da natureza, registrado por Pizango-Paima (1997) foram $13,8 \%$ e 5. Nós registramos, para a mesma espécie, uma prevalência maior $(24 \%)$ e uma intensidade menor (1 - 3) em alevinos. Essas diferenças, podem ter sido influenciadas pelo estágio de vida e pelas condições ambientais em que esses peixes viviam na época da coleta.

Os peixes são infectados com $S$. inopinatus quando ingerem copépodos contendo larvas de nematóide do $3^{\circ}$ e $4^{0}$ estágios (Thatcher, 1991). Os matrinchãs, na natureza, começam a alimentar-se de copépodos a partir de $0,9 \mathrm{~cm}$ de comprimento padrão (Leite, 2000).

Neste trabalho, os peixes da natureza, estavam na fase de alevinos com um comprimento padrão entre 0,8 - $5 \mathrm{~cm}$. Apesar do pequeno tamanho dos peixes, os nematóides apresentavam-se no estágio adulto, indicando que esses hospedeiros foram infectados a partir do momento em que começaram a se alimentar de copépodos.

Thatcher (1991) trabalhando 
com Brycon erythropterus (= Brycon cephalus) adultos da natureza, encontrou oito espécies de monogenóideos. Neste trabalho foi encontrado apenas uma espécie, e os peixes eram alevinos. A diferença na composição das espécies de monogenóideos no trabalho de Thatcher (1991) e neste, mostraram que o parasitismo por outras espécies de monogenóideos, além do $J$. amazonensis, só ocorre em peixes maiores. Ressaltando que o estágio de vida do hospedeiro (jovem, adulto) exerce uma forte influência na composição da fauna parasitológica deste grupo de parasita.

Peixes no estágio de alevinos são mais susceptíveis a doenças branquiais, as quais podem ser desencadeadas por fatores exógenos (Branson, 1993). Infestações massivas de parasitas, na natureza, estão usualmente associadas ao estresse, tornando-os mais propensos a adquirirem infecções (Roberts, 1978).

Aragort \& Moreno (1997) observaram os maiores índices parasitários de Anacanthorus spathulatus Kritsky, Thatcher \& Kayton, 1979 e Linguadactyloides brinkmanni Thatcher \& Kritsky, 1983 no tambaqui em períodos de chuva. Os autores concluíram que as condições climáticas úmidas influenciaram no incremento das cargas parasitárias dessas espécies, propiciando condições favoráveis para a reprodução dos monogenóideos. Estes parasitas, quando se favorecem dos fatores ecológicos desenvolvem-se de forma explosiva e requerem apenas cinco dias para completar o seu ciclo biológico (Soulsby, 1987 apud FloresCrespo et al., 1992).

Neste trabalho, observou-se nos peixes da natureza, infestações massivas por $J$. amazonensis em todos os arcos branquiais, com praticamente a mesma intensidade de infecção. Além do estresse, que esses peixes podem ter sido submetidos, outros fatores podem ter contribuído para a alta infestação deste parasita. Esses alevinos foram capturados em um período de grande ocorrência de chuvas, o qual pode ter propiciado uma maior proliferação desta espécie.

Os protozoários Trichodina sp. tem uma ampla distribuição e afetam a maioria dos peixes de água doce $\mathrm{e}$ marinhos. A doença mostra sinais típicos, com o excesso de produção de muco, erosão das brânquias e pele. Suas populações aumentam rapidamente quando o peixe está debilitado ou em qualidade de água adversa. Esses protozoários são considerados parasitas facultativos, que em condições favoráveis tornamse parasitas (Souza et al., 1997).

A prevalência de Trichodina sp. nos peixes da natureza foi baixa $(2,2)$, e evidenciada nos indivíduos com altas infestações de $J$. amazonensis. Provavelmente, o excesso de muco nas brânquias possa ser devido a infestação conjunta por esses dois grupos de parasitas. A sua ocorrência na natureza pode estar associada aos altos índices de infecção por monogenóideos, os quais podem ter debilitado os hospedeiros, deixando-os mais susceptíveis. 
Houve variação na composição da fauna parasitógica e nos índices de infestação nos peixes provenientes da natureza e examinados após 30 dias na estação de piscicultura. Na natureza observamos seis grupos de parasitas (Trematoda, Nematoda, Monogenoidea, Cestoda, Acanthocephala e Protozoa). Na estação de piscicultura encontramos quatro. Os únicos dois grupos que não ocorreram na estação de piscicultura foram Protozoa e Cestoda. Os baixos valores de prevalência de Trichodina sp. $(13,3)$ e cestódeos $(1,47)$, podem ter dificultado a sua detecção. Os cestódeos são parasitas heteroxênicos, ou seja, necessitam de hospedeiro definitivo e intermediário para propagação do seu ciclo de vida, fato este, que pode ter influenciado na sua distribuição. O próprio ambiente aquático artificial pode ter sido limitante para a propagação deste parasita.

A fauna de monogenóideos dos peixes da estação de piscicultura foi a mesma encontrada na natureza, representada por uma única espécie, $J$. amazonensis. Este parasita apresentou maior prevalência e abundância média na piscicultura e maior indice de intensidade média na natureza.

$\mathrm{Na}$ estação de piscicultura foi encontrado a mesma espécie de nematóide da natureza, $S$. inopinatus, com indices parasitários similares. Os trematódeos tiveram sua prevalência reduzida mais que a metade na estação de piscicultura, mas, apresentaram valores de intensidade média bem próximos. A redução deste índice pode ter sido influenciada pelo estágio larval deste parasita, o qual, não encontrou condições favoráveis para o seu desenvolvimento. Os acantocéfalos obtiveram um aumento de prevalência na piscicultura, de $0,73 \%$ para $3 \%$, porém a intensidade de infestação permaneceu a mesma.

O tempo de permanência de 30 dias na estação de piscicultura, pode não ter sido suficiente, para que maiores modificações, tanto na composição da fauna parasitológica, como nos indices parasitários fossem melhor observados. O exame da parasitofauna de alevinos de $B$. cephalus da natureza, evidenciou que os peixes nessa faixa etária apresentaram altas prevalências pelo monogenóideo Jainus amazonensis. Em vista disso, recomenda-se um período de quarentena, para observações e tratamentos adequados antes dos peixes serem incorporados aos estoques das pisciculturas.

\section{AGRADECIMENTOS}

Ao convênio Capes/The British Council/INPA, responsável pelo financiamento parcial do projeto "Desenvolvimento da Aquacultura no Amazonas", o qual este trabalho esteve inserido. A Coordenação de Pesquisas em Aquacultura do INPA pelo auxilio das coletas na natureza e doação dos peixes.

\section{Bibliografia citada}

Amato, J.F.R; Boeger, W.A.; Amato, S.B. 1991. Protocolos para laboratório-Coleta 
e Processamento de Parasitos de Pescado. Universidade Federal do Rio de Janeiro, Rio de Janeiro, Brasil. 81p.

Aragort, W.C; Moreno, L.G. 1997. Indices epidemiologicos de trematodos monogeneticos en branquias de Colossoma macropomum bajo cultivo. Acta Biologica Venezuelana, 17(1):1-8.

Bier, O. 1975. Bacteriologia e imunologia, em suas aplicações à medicina e a higiene. 16 ed. Edições Melhoramento. Ed. da Universidade de São Paulo, SP, Brasil. $1056 \mathrm{p}$.

Branson, E. 1993. Environmental Aspects of Aquaculture. In: Brown, L. (Ed.). Aquaculture for Veterinarians: fish husbandry and medicine. Pergamon Press. New York, USA. p.57-67.

Bush, A.O.; Lafferty, K.D.; Lotz, J.M.; Shostak, A.W. 1997. Parasitology meets ecology on its own terms: Margolis et al. Revisited. Journal of Parasitology, 83(4):575-583.

Flores-Crespo, J;; lbarra, F; Flores-Crespo, R.; Vasquez, C.G. 1992. Variación estacional de Dactylogyrus sp. en dos localidades productoras de tilapia del Estado de Morelos. Técnica Pecuaria en México, 30(2):109-118.

Kritsky, D.C.; Thatcher, V.E.; Kayton, R.J. 1980. Neotropical Monogenoidea. 3. Five new species from South America with the proposal of Tereancistrum gen. $\mathrm{n}$. and Trinibaculum gen. n. (Dactylogyridae: Ancyrocephalinae). Acta Amazonica, 10(2):411-417.

Leite, R.G. 2000. Alimentação e fontes autotróficas de energia das larvas de peixe do rio Solimões/Amazonas e suas áreas inundáveis. Tese de doutorado, Instituto Nacional de Pesquisas da Amazônia/Fundação Universidade do Amazonas, Manaus, Amazonas, 118p.

Malmberg, G. 1970. The excretory systems and the marginal hooks as a basis for the systematies of Gyrodactylus (Trematoda, Monogenea). Arki för. Zoologi, 2(23): 1- 235 .
Malta, J.C.O. 1984. Os peixes de um lago de várzea da Amazônia Central (lago Janauacá, rio Solimões) e suas relações com os crustáceos ectoparasitas (Branchiura: Argulidae). Acta Amazonica, 14(3-4):355-372,

Malta, J.C.O. 1981. Os crustáceos branquiúros e suas interrelações com os peixes do lago do Janauacá, AM, Brasil (Crustacea: Argulidae). Dissertação de Mestrado, Instituto Nacional de Pesquisas da Amazônia/Fundação Universidade do Amazonas, Manaus, Amazonas. 88p.

Margolis, L.; Esch, G.W.; Holmes, J.C.; Kuris, A.M.; Schad, G.A. 1982. The use of ecological terms in parasitology (Report of an ad Hoc committee of the American Society of Parasitologists). Journal of Parasitology, 68(1):131-133.

Obiekezie, A.I.; Taege, M. 1991. Mortalities in hatchery reared fry of the african catfish, Clarias gariepinus (Burchell), caused by Gyrodactylus groschafti Ergens, 1973. Bulletin Europeo Association of Fish Pathology, 11:82-85.

Pavanelli, G.C.; Eiras, J.C.; Takemoto, R.M. 1998. Doenças de Peixes: Profilaxia, Diagnóstico e Tratamento. EDUEM: Universidade Estadual de Maringá, Maringá, Brasil. 264p.

Pizango-Paima, E.G, 1997. Estudo da alimentação e composiçào corporal do matrinchã Brycon cephalus (Günther. 1869) (Characiformes, Characidae) na Amazônia Central, Dissertação de Mestrado, Instituto Nacional de Pesquisas da Amazônia/Fundação Universidade do Amazonas, Manaus, Amazonas. 71p.

Rego, A.A.; Chubb, J.C.; Pavanelli, G.C. 1999. Cestodes in South American freshwater teleost fishes: keys to genera and brief description of species. Revista Brasileira de Zoologia, 16(2):299-367.

Roberts, R.J. 1978. Fish Pathology. $2^{\mathrm{a}}$ edição, Balliere Tindall, Philadelphia, USA. 318p.

Shinn, A.P.; Gibson, D.I; Sommerville, C. 1993. An SEM study of the haptoral sclerites of the genus Gyrodactylus Nordmann, 1832 (Monogenea) following extraction 
by digestion and sonication techniques.

Systematic Parasitology,

$25: 135-$

144.

Southgate, P. 1993. Disease in Aquaculture. In:

Brown, L. (Ed.). Aquaculture for Veterinarians: fish husbandry and medicine. Pergamon Press, New York, USA. p. 91-129.

Souza, M.L.R.; Martins, M.L.; Santos, J.M. 1997. Scanning electronic microscopy of Trichodina spp. in branchiae of the pacu Piaractus mesopotamicus. Acta Microscopica, 6:516-517.

Thatcher, V.E. 1991. Amazon Fish Parasites. Amazoniana, 11(3/4):263-572.

Zaniboni-Filho, E.; Carvalho, J.L.; VillacortaCorrea, M.A.E.; Rezende, E.K. 1988. Caracterização morfológica do matrinchã, Brycon cephalus (Günther, 1869) (Teleostei: Characidae). Revista Brasileira de Biologia, 48(1):41-50. 